\title{
STIMULATION BY CATECHOLAMINE OF PURINE CATABOLISM IN RATS AND CHICKENS
}

\author{
Yukio YONETANI, Mitsuo ISHII and Yasunao OGAWA \\ Shionogi Research Laboratory, Shionogi \& Co., Lid., \\ rukushima-ku, Osaka 553, Japan
}

Accepted September 11, 1978

\begin{abstract}
The effect of catecholamine in vivo was studied on purine catabolism in rats and chickens. Catecholamine, administered intraperitoneally in a high dose, markedly increased plasma uric acid and allantoin in rats, and an increase was also observed with intravenous infusion of a lower dose of catecholamine. The effects of catecholamine were characterized by inhibition with alpha and beta adrenoceptor antagonists. Regarding the mechanism of this catecholamine action on purine catabolism, it was shown that catecholamine stimulated degradation of tissue ATP into the end-product. Plasma allantoin, the final purine catabolite in rats, elicited by catecholamine could be maintained under conditions of renal failure, although the action of catecholamine in intact rat was short lasting. The effect of catecholamine was potentiated and/or prolonged by angiotensin-II and aminophylline, and a hyperuricemic state could be induced by catecholamine treatment in chickens. In addition, increase of plasma purine catabolite by immobilization stress in rats suggested the involvement of endogenous catecholamine. From these experimental results, it is considered that catecholamines probably play a important role in the pathogenesis of hyperuricemia.
\end{abstract}

The effect of catecholamine on purine catabolism in vivo has apparently not yet been reported in detail. Demartini (1) described that uric acid clearance in man may be reduced by the renal vasoconstricting action of alpha adrenoceptor agonists, and warned about their role in the induction of hyperuricemia. However, he provided no evidence that hyperuricemia was directly related to catecholamine. We recently demonstrated a notable increase of plasma uric acid in rats given intraperitoneal administration of epinephrine, and inhibition of the increase by the pretreatment with alpha adrenoceptor antagonists (2). Further, it was suggested that the increase of plasma uric acid was due to the rapid breakdown of hepatic and intestinal ATP rather than the renal vasoconstriction (3), and that the increase of plasma purine catabolites was also caused by the action of beta adrenoceptor agonists.

The present paper is a report of our studies on the stimulation of purine catabolism by catecholamine.

\section{MATERIALS AND METHODS}

Seven week-old male Wistar rats were housed in metal cages with sawdust as bedding and were maintained on a solid diet CA-1 (Japan CLEA Co., Tokyo) and tap water ad libitum. The room was air-conditioned, kept at a temperature of $252 \mathrm{C}$ with a relative humidity of $55.5 \%$, and was lighted artificially from 6:00 to 18:00. Mechanical ventilation of the room was set at the rate of twelve changes per hour. The rats were decapitated, and 
blood was collected in heparinized centrifuge tubes and kept in an ice bath. The plasma was separated by centrifuging at $3,000 \mathrm{rpm}$ for 10 min. Plasma uric acid was colorimetrically determined by the method of Eichhorn et al. (4). Plasma allantoin was estimated by the method of Young and Conway (5) with a modification for preventing false estimation based upon plasma components, such as glucose, lactate and uric acid. The mixture containing $0.2 \mathrm{ml}$ of plasma, $0.5 \mathrm{ml}$ of $0.5 \mathrm{~N}$ sodium hydroxide and $2.3 \mathrm{ml}$ of water was heated for $7 \mathrm{~min}$ in a boiling water bath. After being cooled in an ice-cold bath, $0.3 \mathrm{ml}$ of $1 \mathrm{~N}$ sulfuric acid and $1.7 \mathrm{ml}$ of $2 \%(\mathrm{~W} / \mathrm{V})$ sodium tungstate- $1 / 3 \mathrm{~N}$ sulfuric acid mixture $(5: 2)$ were added. This preparation was centrifuged, and $3.0 \mathrm{ml}$ of the supernatant fluid was used for the colorimetric determination with phenylhydrazine and ferricyanide in the acidic medium reported by Young and Conway (5).

In experiments using rats with ligated ureters, the operation was performed under deep anesthesia with $65 \mathrm{mg} / \mathrm{kg}$ of pentobarbital i.p. The infusion of agents was carried out in the anesthetized animals through the femoral vein. The method for applying immobilization stress was as follows: rats were fixed in a supine position on a board and their legs were tied. It is important to keep the experimental environment possibly quiet in order to avoid other stress, and in each experiment two groups of rats, control and treated, were utilized for an accurate comparison.

To determine ATP levels, tissues were removed, weighed and homogenized with $5 \%$ $(\mathrm{W} / \mathrm{V})$ ice-cold perchloric acid to obtain from 2 to $10 \%(\mathrm{~W} / \mathrm{V})$ homogenate according to the content of ATP. This procedure was carried out within a minute after decapitation. The homogenate was centrifuged for $15 \mathrm{~min}$ at $3,000 \mathrm{rpm}$, then part of the supernatant fluid was pipetted into the centrifuge tube and recentrifuged after neutralization with $5 \mathrm{~N}$ potassium carbonate solution. This material was used to determine the ATP content by fluorophotometric procedure using the hexokinase-glucose-6-phosphate dehydrogenase system (6).

In experiments on chickens, white Leghorn hens weighing $1-1.5 \mathrm{~kg}$ were used. The animals were provided a commercial diet for adult animals ad libitum and drinking water was automatically supplied from 6:00 to 18:00. Blood was collected from a vein under the wings, about $0.5 \mathrm{ml}$ in each withdrawal. Separation of plasma and estimation of uric acid were carried out as described above.

All agents used were commercial preparations: 1-epinephrine (Merck), dl-isoproterenol sulfate (Sigma), 1-epinephrine hydrochloride solution for injection (Sankyo), 1-isoproterenol hydrochloride solution for injection (Nikken Kagaku), dl-propranolol hydrochloride (Sigma), phenoxybenzamine hydrochloride (Nakarai Kagaku), reserpine (CIBA), allopurinol (Sigma), aminophylline (Torii Yakuhin) and angiotensin-ll (Protein Research Foundation, Osaka). 1-Epinephrine was dissolved with diluted hydrochloric acid and neutralized with diluted sodium hydroxide solution just before use. Angiotensin-II was dissolved with saline, catecholamine solutions for injection were diluted with saline and others were dissolved or suspended in water. These agents were administered at $0.2 \mathrm{ml} / \mathrm{kg}$ i.p. or s.c., and at $0.5 \mathrm{ml} /$ $\mathrm{kg} \mathrm{p.o.} \mathrm{in} \mathrm{rats,} \mathrm{and} \mathrm{at} 0.5 \mathrm{mg} / \mathrm{kg}$ s.c. in chickens. 


\section{RISUITS}

When 1-epinephrine was given i.p. to rats, the level of plasma uric acid rapidly increased, resulting in elevation of plasma allantoin, while $\mathrm{dl}$-isoproterenol gradually increased allantoin with a slight increase of uric acid in the early stage of the administration (Fig. 1).

1-Norepinephrine also showed an effect similar to that seen with epinephrine, except for the absence of marked elevation of allantoin in the latter stage. 1-Phenylephrine produced effects much like those seen with norepinephrine, except that a higher dose was required. A higher dose of subcutaneously injected epinephrine was required to show the same effect as that of intraperitoneal administration. Figure 2 demonstrates that the effects of epinephrine and isoproterenol differed regarding the pattern of uric acid and allantoin in the early stage of all effective dose-range.

In addition, this figure shows that increases of purine catabolites were detectable with a lower dose of catecholamine. Intravenous injection of catecholamine revealed such effects with low doses, but these effects immediately disappeared. With an intravenous infusion, a lower dose of catecholamine increased the level of plasma purine catabolites (Table 1).

The characteristics of these effects of catecholamine were studied under the pretreatment with adrenoceptor antagonists. Phenoxybenzamine inhibited the increase of uric acid by epinephrine i.p., while propranolol inhibited the increases of uric acid and allantoin by
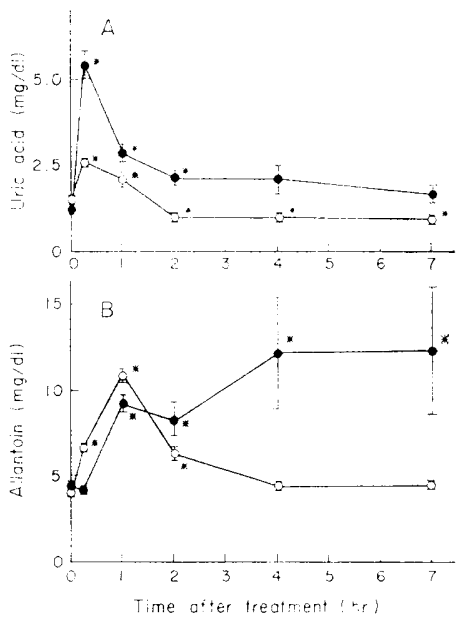

FIC. 1. Changes in plasma purine catabolites after catecholamine administration in rats. l-Epinephrine $(1 \mathrm{mg} \mathrm{kg}$, filled plot) and dl-isoproterenol (2 $\mathrm{mg} / \mathrm{kg}$, open plot) were administered intraperitoneally. Panel A indicates uric acid and $B$ allantoin. Each point represents the mean S.E. of six or seven rats. *: Significantly different from control value at $\mathrm{P}-0.01$

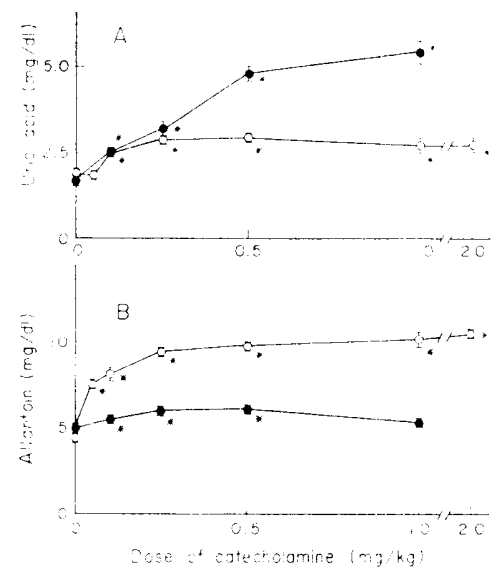

FIG. 2. Relation between the doses of catecholamine and their effects on plasma purine catabolites in rats. Each plot shows the value at 15 min after 1 -epinephrine administration i.p. (filled plot) and at 30 min after dl-isoproterenol i.p. (open plot). Panel $A$ indicates uric acid and $B$ allantoin. Each point represents the mean S.F. of six or seven rats. * Significantly different from the group without catecholamine at P. -0.01 . 
TABLE 1. Effect of intravenous infusion of catecholamine on plasma purine catabolites in rats

\begin{tabular}{|c|c|c|c|}
\hline $\begin{array}{l}\text { Catecholamine } \\
(, / \mathrm{g} / \mathrm{kg} / \mathrm{min})\end{array}$ & $\mathrm{N}$ & $\begin{array}{l}\text { Uric acid } \\
(\mathrm{mg} / \mathrm{dl})\end{array}$ & $\begin{array}{l}\text { Allantoin } \\
(\mathrm{mg} / \mathrm{dl})\end{array}$ \\
\hline Control (saline) & 8 & $1.19+0.06$ & $5.32 \approx 0.14$ \\
\hline 1-1 pinephrine (5) & 7 & $1.43: 0.08 *$ & $5.89 \div 0.11^{*}$ \\
\hline 1-Isoproterenol (1) & 6 & $2.050 .13^{* *}$ & $7.18 \bigcirc 0.14^{* *}$ \\
\hline 1-Isoproterenol (5) & 5 & $1.9910 .12^{* *}$ & $7.92: 0.36^{* *}$ \\
\hline
\end{tabular}

Catecholamine hydrochloride solutions diluted with saline were infused for 15 min at a flow rate of $1 \mathrm{ml} / 15 \mathrm{~min}$ into the femoral vein in rats anesthetized with $65 \mathrm{mg} / \mathrm{kg}$ of pentobarbital, i.p. Animals were decapitated immediately after infusion. Data represent the mean $\ldots$ S.E. *: Significantly different from control group at $\mathrm{P}<0.05$. **: Significantly different from control group at $\mathrm{P}<0.01$.

TABLF 2. Effects of adrenoceptor antagonists on plasma purine catabolites elicited by catecholamine in rats

\begin{tabular}{|c|c|c|c|}
\hline Treatment & $N$ & $\begin{array}{l}\text { Uric acid } \\
\text { (mg/dl) }\end{array}$ & $\begin{array}{l}\text { Allantoin } \\
\text { (mg/dl) }\end{array}$ \\
\hline Control & 4 & $0.56-0.07$ & $5.36 \div 0.21$ \\
\hline Phenoxybenzamine & 5 & $0.34 \cdots 0.02 *$ & $5.91 \div 0.15$ \\
\hline Propranolol & 5 & $0.47 \ldots 0.01$ & $5.88 \div 0.04 \%$ \\
\hline 1-Epinephrine & 6 & $3.11 \cdots 0.36^{* *}$ & $7.55-0.31^{\text {** }}$ \\
\hline Phenoxybenzamine 1-Epinephrine & 6 & $0.95+0.10 *(* *)$ & $8.10 \div 0.28 \%$ \\
\hline Propranolol 1-Epinephrine & 6 & $2.77-0.45 * *$ & $6.98-0.23 *$ \\
\hline dl-Isoproterenol & 5 & $1.11 \ldots 0.07 *$ & $9.47+0.40^{* *}$ \\
\hline Phenoxybenzamine - dl-Isoproterenol & 5 & $1.26=0.13 * *$ & $9.86+0.33^{* *}$ \\
\hline Propranolol: dl-Isoproterenol & 6 & $0.58 \ldots 0.09(* *)$ & $6.81+0.19 * *(* *)$ \\
\hline
\end{tabular}

Phenoxybenzamine ( $1 \mathrm{mg} / \mathrm{kg}$, i.p.) and propranolol (2 $\mathrm{mg} / \mathrm{kg}$, i.p.) were administered $45 \mathrm{~min}$ before sacrifice, and l-cpinephrine $(0.5 \mathrm{mg} / \mathrm{kg}, \mathrm{i.p}$.) and dl-isoproterenol $(0.2 \mathrm{mg}$ $\mathrm{kg}$, i.p.) were administered 30 min after the pretreatments. Data represent the mean S.E. *: Significantly different from control group at $P$ 0.05. *: Significantly different from control group at $P$ 0.01 (**): Significantly different from catecholamine-treated group at $\mathrm{P}(0.01$.

\section{isoproterenol (Table 2).}

An effect similar to that of phenoxybenzamine was observed with other alpha adrenoceptor antagonists such as dibenamine, tolazoline or dihydroergotamine, and an effect similar to that of propranolol with other beta adrenoceptor antagonists such as pronethalol or dichloroisoproterenol.

Next, studies on the possible correlation of these effects of catecholamine and the cause of hyperuricemia were persued. Clarification has to be made as to whether or not the final purine catabolite elicited by catecholamine can be maintained in plasma. Various attempts carried out in intact rats showed transient effects. In rats with ligated ureters, however, progressive increase of plasma allantoin was observed, and the allantoin levels elevated by catecholamine were retained in addition to those seen with the ligation effect (Fig. 3). 


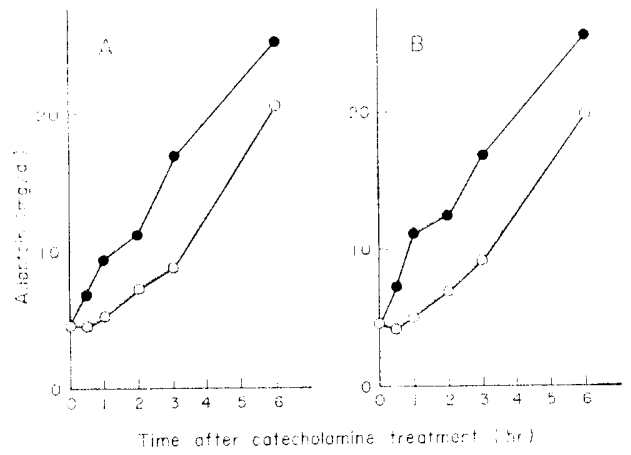

FIG. 3. Plasma allantoin levels after ligation of ureters in rats followed by administration of 1-epinephrine (A) or $\mathrm{dl}$-isoproterenol (B). Ureters were ligated under anesthesia with $65 \mathrm{mg} / \mathrm{kg}$ of pentobarbital i.p., and 1-epinephrine $(0.5 \mathrm{mg} / \mathrm{kg})$ or dl-isoproterenol ( $1 \mathrm{mg} / \mathrm{kg}$ ) was administered i.p. $30 \mathrm{~min}$ after operation. The filled plot represents the mean value of the group (three rats) treated with catecholamine, and the open plot shows that of the group without catecholamine.

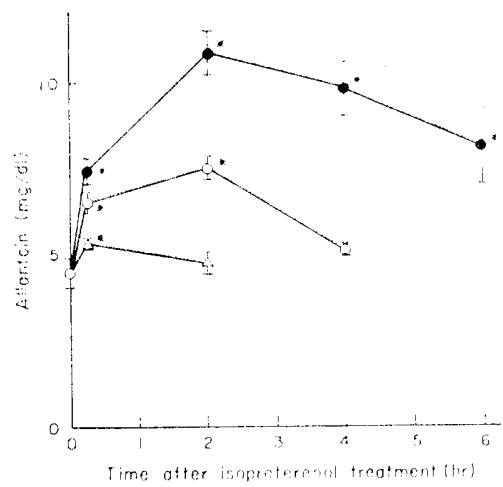

FIG. 4. Effect of angiotensin-II on plasma allantoin elicited by isoproterenol in rats. Angiotensin- II $(2.5 \mu \mathrm{g} / \mathrm{kg} / \mathrm{min})$ was infused for $40 \mathrm{~min}$ at a flow rate of $1 \mathrm{ml} / 45 \mathrm{~min}$ through the femoral vein in animals anesthetized with $65 \mathrm{mg} / \mathrm{kg}$ of pentobarbital, i.p. 1-Isoproterenol hydrochloride solution (1-isoproterenol, $0.2 \mathrm{mg} / \mathrm{kg}$ ) was administered i.p., $10 \mathrm{~min}$ after start of the infusion. The open plot represents the mean value of the group treated with isoproterenol only, the filled plot that of the group treated with angiotensin-II and isoproterenol, and the triangle that of the group treated with angiotensin-II only. Each point represents the mean - -S.E. of five or six rats. The zero time value means the allantoin level of anesthetized animals. *: Significantly different from the group without treatment at $\mathrm{P}<0.01$.

This ligation produced little change in the plasma uric acid level, which returned rapidly to normal even after catecholamine treatments. The animals with a unilateral ligated ureter showed only a slight increase of allantoin, but the catecholamine-induced increases were obviously retained for a longer period than in animals without the ligation. These results support the idea that the effects of catecholamine are significant in the development of hyperuricemia in animals with disorders of excretory function and in which the final product of purine catabolism is uric acid. 
Angiotensin-II given i.v., reportedly an inducer of hyperuricemia (1), slightly elevated the allantoin level in rats, and prolonged the elevation of allantoin levels induced by isoproterenol (Fig. 4).

The allantoin level elevated by epinephrine or uric acid under such infusion was also retained, but the potentiation in the early stage was observed only with the administration of isoproterenol. Aminophylline slightly increased plasma uric acid and allantoin and potentiated the action of isoproterenol (Table 3).

Plasma purine catabolites in intact rats showed the levels fluctuating from 0.5 to $2.0 \mathrm{mg} /$ $\mathrm{dl}$ of uric acid and from 3.0 to $6.0 \mathrm{mg} / \mathrm{dl}$ of allantoin depending on the dietary conditions. Such would explain the lower level of uric acid in the control value seen in Table 2. However, we have observed over the years that plasma purine catabolite levels in rats readily changed under conditions of stress. Fixing rats on a board in a supine position was considered to be a form of stress, and definite increases of allantoin and uric acid in plasma were observed (Fig. 5). Pretreatment with adrenoceptor antagonists slightly reduced these increased levels, and pretreatment with reserpine reduced the effect. In this case, also, aminophylline potentiated the effect of the stress induced by immobilization (Table 4).

TABLE 3. Effect of aminophylline on plasma purine catabolites elicited by isoproterenol in rats

\begin{tabular}{llll}
\hline \multicolumn{1}{c}{ Treatment } & $\mathrm{N}$ & $\begin{array}{c}\text { Uric acid } \\
(\mathrm{mg} / \mathrm{dl})\end{array}$ & $\begin{array}{c}\text { Allantoin } \\
(\mathrm{mg} / \mathrm{dl})\end{array}$ \\
\hline Control & 7 & $1.82=0.03$ & 4.69 .0 .07 \\
Aminophylline & 7 & $1.96 \pm 0.08$ & $6.71 \ldots 0.19^{* *}$ \\
dl-Isoproterenol & 7 & $2.48 \pm 0.11^{* *}$ & $7.13 .0 .14^{* *}$ \\
Aminophylline + dl-Isoproterenol & 7 & $3.14 \pm 0.10^{* *}\left(^{* *}\right)$ & $9.91 \ldots 0.24^{* *}$ \\
\hline
\end{tabular}

Aminophylline (100 mg $\mathrm{kg}$, i.p.) was administered $45 \mathrm{~min}$ before sacrifice, and dlisoproterenol (2 $\mathrm{mg} / \mathrm{kg}$, i.p.) was administered $30 \mathrm{~min}$ after the pretreatment. Data represent the mean - S.E. **: Significantly different from control group at $P-0.01$. $\left(^{* *}\right)$ : Significantly different from isoproterenol-treated group at $\mathrm{P}<0.01$.

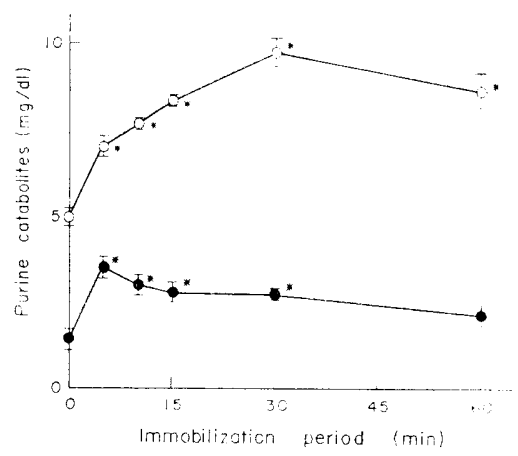

Fig. 5. Effect of immobilization stress on plasma purine catabolites in rats. The filled plot represents uric acid level, and the open plot allantoin level. Each point represents the mean $:$ S.E. of six or seven rats. *: Significantly different from the level before treatment at $\mathrm{P}<0.01$. 
Catecholamine given s.c. produced relatively prolonged increase in the plasma uric acid levels in chickens. As seen in Fig. 6, the effect of a single agent such as epinephrine, isoproterenol or aminophylline was slight, but a marked increase of plasma uric acid was

TaBt 1. 4. Effects of adrenoceptor antagonists, aminophylline and reserpine on plasma purine catabolites elicited by immobilization stress in rats

\begin{tabular}{|c|c|c|c|}
\hline Treatment & $N$ & $\begin{array}{l}\text { Uric acid } \\
\text { (mg/dl) }\end{array}$ & $\begin{array}{l}\text { Allantoin } \\
(\mathrm{mg} / \mathrm{dl})\end{array}$ \\
\hline Control & 7 & $1.18 \div 0.05$ & $5.22 \div 0.12$ \\
\hline Stress & 6 & $2.47 \therefore 0.14 * *$ & $9.37 \ldots 0.33^{* *}$ \\
\hline Phenoxybenzamine & 8 & $1.22 \div 0.05$ & $6.14 \div 0.15^{* *}$ \\
\hline Phenoxybenzamine Stress & 6 & $1.95 \div 0.07^{* *}(*)$ & $9.19-0.20^{* *}$ \\
\hline Propranolol & 7 & $1.41=0.05$ & $6.25=0.20^{* *}$ \\
\hline Propranolol Stress & 6 & $2.15 \div 0.09 * *$ & $8.43 \div 0.15^{* *}(*)$ \\
\hline Control & 7 & $1.87: 0.09$ & $4.39 \div 0.09$ \\
\hline Stress & 6 & $2.89-0.14^{* *}$ & $7.34 \div 0.19^{* *}$ \\
\hline Aminophylline & 6 & $2.11: 0.05$ & $5.66 \div 0.24^{* *}$ \\
\hline Aminophylline $i$ Stress & 6 & $3.69 \div 0.18^{* *}(*)$ & $9.12-0.19^{* *}$ \\
\hline Control & 8 & $1.25: 0.06$ & $3.75 \div 0.05$ \\
\hline Stress & 6 & $1.97 \div 0.08 * *$ & $6.150 .17^{* *}$ \\
\hline Reserpine & 8 & $1.25 \quad 0.09$ & $3.58 \div 0.09$ \\
\hline Reserpine Stress & 6 & $1.51 \quad 0.09$ & $4.60-13^{* *}(*)$ \\
\hline
\end{tabular}

Phenoxybenzamine (10 mg/kg, i.p.), propranolol (10 $\mathrm{mg} / \mathrm{kg}$, i.p.) and aminophylline (100 mg/kg, i.p.) were administered $45 \mathrm{~min}$ before sacrifice, and reserpine $(2.5 \mathrm{mg} / \mathrm{kg}$, i.p.) was given twice on the day before giving stress, which was carried out for $15 \mathrm{~min}$. Data represent the mean :S.E. **: Significantly different from control group at P. 0.01. (*): Significantly different from stressed group at $\mathrm{P}<0.05$.

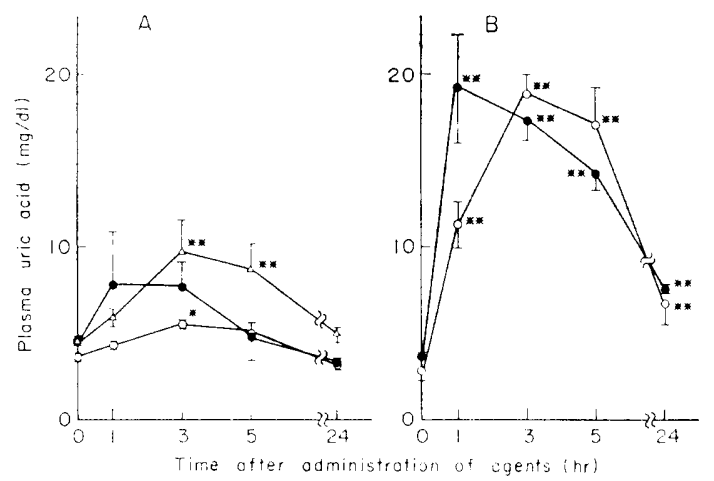

Fici. 6. Effects of aminophylline and catecholamine on plasma uric acid in chickens. Aminophylline (50 $\mathrm{mg} \mathrm{kg}$, s.c.), 1-epinephrine (1 $\mathrm{mg} / \mathrm{kg}, \mathrm{s.c}$ ) and $\mathrm{dl}$-isoproterenol $(2 \mathrm{mg}$. $\mathrm{kg}$, s.c.) were administered. The effect of a respective agent is shown in panel $A$ by filled plots (epinephrine), open plots (isoproterenol) and triangles (aminophylline). The effect of simultaneous administration of aminophylline and epinephrine (filled plots) and that of aminophylline and isoproterenol (open plots) are shown in panel B.: Each point represents the mean \pm S.E. of four animals. *: Significantly different from control value at $\mathrm{P}<0.05$. **: Significantly different from control value at $\mathrm{P}<0.01$. 
observed with a concomitant administration of aminophylline and catecholamine.

Allopurinol, an inhibitor of xanthine oxidase (7), inhibited in rats increases in plasma purine catabolites elicited by catecholamine (Table 5).

Differences of plasma purine catabolite levels in the blood from portal vein, abdominal aorta and hepatic vein were examined. The most marked increase of uric acid in the early stage after epinephrine administration i.p. was seen in the blood from portal vein, with the next highest level seen in the arterial blood. However, there was little difference in plasma purine catabolite levels in the blood from abdominal aorta and that of hepatic vein following epinephrine treatment (Table 6).

TABLE 5. Effect of allopurinol on plasma purine catabolites elicited by catecholamine in rats

\begin{tabular}{llll}
\hline \multicolumn{1}{c}{ Treatment } & $\mathrm{N}$ & $\begin{array}{c}\text { Uric acid } \\
(\mathrm{mg} / \mathrm{dl})\end{array}$ & $\begin{array}{c}\text { Allantoin } \\
(\mathrm{mg} / \mathrm{dl})\end{array}$ \\
Control & 6 & $1.41 \pm 0.04$ & $3.95 \pm 0.09$ \\
Allopurinol & 6 & $0.34 \pm 0.03^{* *}$ & $2.42 \pm 0.08^{* *}$ \\
1-Epinephrine & 7 & $3.20 \pm 0.17^{* *}$ & $6.83 \pm 0.36^{* *}$ \\
Allopurinol +1 -Epinephrine & 7 & $0.49 \pm 0.05^{* *}(* *)$ & $3.13 \pm 0.13^{* *}(* *)$ \\
dl-Isoproterenol & 7 & $2.21 \pm 0.12^{* *}$ & $10.19 \pm 0.12^{* *}$ \\
Allopurinol $+\mathrm{dl}-$ Isoproterenol & 7 & $0.30 \pm 0.05^{* *}\left({ }^{* *}\right)$ & $3.52 \pm 0.09^{* *}(* *)$ \\
\hline
\end{tabular}

Allopurinol $(100 \mathrm{mg} / \mathrm{kg}$, p.o.) was administered $120 \mathrm{~min}$ before sacrifice, and 1-epinephrine $(0.5 \mathrm{mg} / \mathrm{kg}$, i.p.) and dl-Isoproterenol $(2 \mathrm{mg} / \mathrm{kg}$, i.p. $)$ were administered 90 min after allopurinol treatment. Data represent the mean S.E. ${ }^{* *}$ : Significantly different from control group at $\mathbf{P}<0.01 .\left(^{* *}\right)$ : Significantly different from catecholamine-treated group at $\mathrm{P}<0.01$.

TABLE 6. Concentrations of purine catabolites in plasma from portal vein, hepatic vein and abdominal aorta in rats administered epinephrine

\begin{tabular}{ccccc}
\hline $\begin{array}{c}\text { Time after } \\
\text { treatment } \\
(\mathrm{min})\end{array}$ & $\mathrm{N}$ & Portal vein & $\begin{array}{c}\text { Plasma from } \\
\text { Hepatic vein }\end{array}$ & Abdominal aorta \\
\hline & & & Uric acid $(\mathrm{mg} / \mathrm{dl})$ \\
0 & 5 & $1.64 \pm 0.09$ & $2.03 \pm 0.17$ & $2.42 \pm 0.10$ \\
15 & 5 & $10.26 \pm 0.47^{* *}$ & $6.88 \pm 0.41^{* *}$ & $7.35 \pm 0.29^{* *}$ \\
60 & 5 & $4.40 \pm 0.48^{* *}$ & $3.47 \pm 0.45^{* *}$ & $4.80 \pm 0.58^{* *}$ \\
120 & 4 & $4.01 \pm 0.31^{* *}$ & $3.51 \pm 0.27^{* *}$ & $3.76 \pm 0.22^{* *}$ \\
& & & Allantoin $(\mathrm{mg} / \mathrm{dl})$ & \\
0 & 5 & $3.58 \pm 0.12$ & $4.48 \pm 0.10$ & $4.07 \pm 0.09$ \\
15 & 5 & $5.02 \pm 0.18^{* *}$ & $4.68 \pm 0.34$ & $4.82 \pm 0.23^{* *}$ \\
60 & 5 & $8.97 \pm 0.34^{* *}$ & $9.86 \pm 0.27^{* *}$ & $9.04 \pm 0.33^{* *}$ \\
120 & 4 & $12.55 \pm 0.46^{* *}$ & $12.18 \pm 0.31^{* *}$ & $10.73 \pm 0.56^{* *}$ \\
\hline
\end{tabular}

Animals were anesthetized with pentobarbital, $65 \mathrm{mg} / \mathrm{kg}$ given i.p., $10 \mathrm{~min}$ before sacrifice, laparotomized and about $0.8 \mathrm{ml}$ of blood was collected from respective vessels. Blood was obtained first from the portal vein, next from the hepatic vein nearby the inferior vena cava and lastly from the abdominal aorta. 1-Epinephrine $(1 \mathrm{mg} / \mathrm{kg}$ ) was given i.p. Data represent the mean \pm S.E. **: Significantly different from zerotime value at $\mathrm{P}<0.01$. 


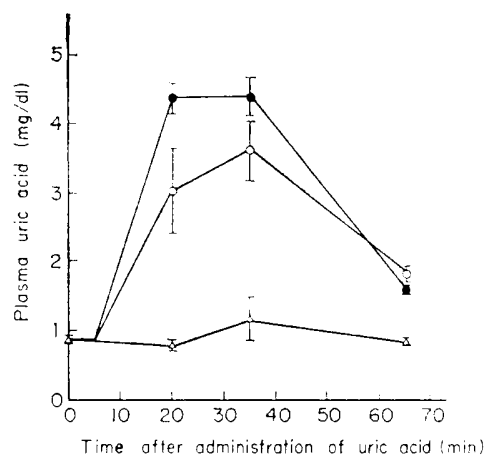

Fici. 7. Effect of exogenous uric acid on epinephrinc-induced elevation of plasma uric acid in rats. 1-Epinephrine $(1 \mathrm{mg} / \mathrm{kg}$, j.p.) was administered 5 min after uric acid treatment (200 $\mathrm{mg} / \mathrm{kg}$, p.o.). The filled plot show's plasma uric acid level in rats administered uric acid and epinephrine (a), the open plot that in rats administered epinephrine only (b), and the triangle plot that in rats administered uric acid only. Each point represents the mean S.E. of eight animals. The differences between (a) and (b) are statistically not significant in respective time after administration.

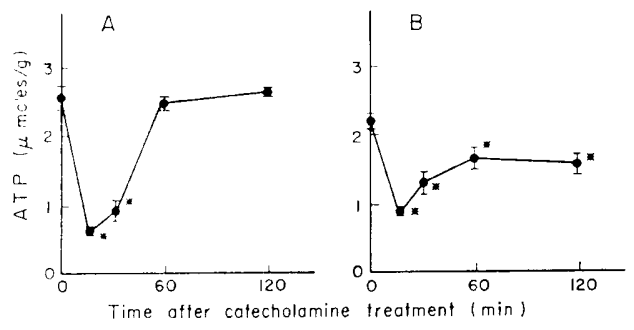

FIG. 8. Effects of 1-epinephrine on hepatic ATP (A) and of dl-isoproterenol on cardiac ATP (B) in rats. 1-Epinephrine (1 $\mathrm{mg} / \mathrm{kg}$, i.p.), and dl-isoproterenol (2 $\mathrm{mg} k \mathrm{~kg}$, i.p.) was administered. Each point represents the mean $:$ S.E. of eight animals. *: Significantly different from control value at $\mathrm{P}<0.01$.

As shown in Fig. 7, orally administered uric acid had no significant effect on the increase in plasma uric acid induced by epinephrine.

A breakdown in the levels of ATP in tissues occurs rapidly in states of ischemia and/or hypoxia $(8,9)$. As shown in Fig. 8, epinephrine administered i.p. resulted in a reduction in ATP levels in the liver, while isoproterenol reduced these levels in the heart.

Epinephrine administered i.p. in doses over $0.5 \mathrm{mg} / \mathrm{kg}$ also reduced ATP level in the intestine. On the contrary, ATP levels in the intestine or the liver were not reduced and there was only a slight reduction in these levels in the heart with subcutaneous administration. A similar decrease in the ATP levels in the heart was observed even with administration of phenylephrine given i.p. The effect of isoproterenol on cardiac ATP level was detectable at the dose over $0.1 \mathrm{mg} / \mathrm{kg}$ i.p. Moreover, these effects of catecholamine were inhibited by pretreatment with adrenoceptor antagonists.

\section{DISCUSSION}

The objective of the present study was to search for the stimulative effect of catecholamine on purine catabolism and the possible pathogenesis of hyperuricemia. Demartini (1) suggested that epinephrine, norepinephrine and angiotensin-II were inducers of hyperuricemia because of their renal vasoconstricting actions, and further clinical studies showed a striking association between hyperuricemia and hypertension $(10,11)$. Recently, Wallace 
(12) reported increases of renin and catecholamine in the blood of patients with gout after salt-loading.

We demonstrated herein the effects of catecholamine by both alpha and beta adrenoceptor agonists. However, inhibitory effect of allopurinol on the catecholamine action might mean that catecholamine enhanced production of purine catabolites. Moreover, the data in Table 6, Fig. 7 and Fig. 8 show that the effects of catecholamine in high doses resulted from circulatory change and the increases of purine catabolites were probably the consequence of breakdown of ATP in the anoxial tissue. In this work, the materials for estimating tissue ATP level were prepared without rapid freezing in order to avoid an obvious decrease in the intensity of catecholamine action under states of anesthesia. However, the contents of ADP and AMP determined by Adam's method (13) did not indicate increases compensative to the decrease of ATP level in the materials prepared from animals given catecholamines. In addition, there were no increases of nucleosides and bases in the materials when examined by chromatography using a Sephadex G-10 column. From these results and prior work by Kammermeier et al (14), it could be concluded that breakdown of tissue ATP was caused by the administration of high doses of catecholamine, even if the primary effect on circulatory change differed between alpha and beta adrenoceptor agonists.

Potentiation of catecholamine action by angiotensin-II has been well investigated (15, 16), and Kuchel et al (17) indicated a state potentiating action of catecholamine, especially the action of beta adrenoceptor agonist, in hypertension. In fact, our experimental result in rats presented obvious potentiation and prolongation of the increase of plasma allantoin induced by isoproterenol.

On the other hand, Rockson et al (18) reported a marked increase of plasma dopamine beta-hydroxylase activity in hypoxanthine-guanine phosphoribosyl transferase-deficient subjects and suggested the role of catecholamine in hyperuricemia. Sakata and Fuchimoto (19) reported the aggressive behavior induced by a sustained high dose of theophylline in rats. The fact that an obvious hyperuricemia was induced in chickens given aminophylline and catecholamine is interesting in relation to these observations. However, we could not obtain an experimental model of a long lasting hyperuricemic state, because of the potent diuretic action of aminophylline.

Whether or not stimulation of purine catabolism is induced by endogenous catecholamine remains to be investigated. The results in stressed rats suggested enhanced endogenous catecholamine in the increases of plasma purine catabolites, but the effects of adrenoceptor antagonists therein were weaker than those expected from the experiments with exogenous catecholamine. The present results indicate that hyperuricemia may be attributed to causes different from those heretofore considered. 


\section{REFERENCES}

1) Drmartini, F.E.: Hyperuricemia induced by drugs. Arth. Rheum. 8, 823-829 (1965)

2) Yonetani, Y., DOLzaki, T. aNd OGaWA, Y.: Epinephrine-induced hyperuricemia in experimental animals. (hem. Pharm. Bull. 25, 441-447 (1977)

3) Yonetan, Y., IShit, M., Yamada, K. ANd OGawa, Y.: Origin of plasma uric acid induced by 1-epinephrine. Chem. Pharm. Bull. 25, 457-463 (1977)

4) Eichirorn, F., Zflmanowski, S., Lew, E., Rutenberg, A. and Fanlas, B.: Improvement of the uric acid determination by the carbonate method for serum and urine. J. clin. Path. 14, 450-452 (1961)

5) Young, E.G. AND Conway, D.F.: On the estimation of allantoin by the Rimini-Schryver Reaction. J. biol. Chem. 142, 839-853 (1942)

6) Greengard, P.: Methods of Enzymatic Analysis, Edited by Bergmeyer, H.U., p. 551-558, Academic Press, New York and London (1963)

7) Rundles, R.W., Wyngadden, J.B., Hitching, G.H. and Elion, G.B.: Drugs and uric acid. A. Rev. Pharmacol. 9, 345-362 (1969)

8) Deuticke, B., Grriach, F. and Dierkmann, R.: Abbau freier Nucleotide in Herz, Skeletmuskel, Gehirn und Leber der Ratte bei Sauerstoffmangel. Pfügers Arch. 292, 239254 (1966)

9) Wusch, F., Borcktr, I.M. ANd Martinez, B.: Abbauwege und Abbaumuster der Purinenucleotide in Herz-, Leber-, und Nierengewebe von Kaninchen nach Kreislaufstillstand. Biochem. Biophys. Acta 166, 547-556 (1968)

10) Breckevridge, A.: Hypertension and hyperuricemia. Lancet 1, 15-18 (1966)

11) Cannon, P.I., Stason, W.B.. Dhmartini, F.E., Sommers, S.C. and Laragh, J.H.: Hyperuricemia in primary and renal hypertension. New Engl. J. Med. 275, 457-464 (1966)

12) Wal.tace, S.L.: Gout and hypertension. Arth. Rheum. 18, 721-723 (1975)

13) AdAm, H.: Methods of Enzymatic Analysis, Edited by Bergmeyer, H.U., p. 573-577, Academic Press, New York and London (1963)

14) Kammermeifer, H., Blfnger, R., Ziegler, V. and Gerlach, E.: Vergleichende Untersuchungen über den Einfluß von Oxyfedrin, Adrenalin und Digitalisglykosiden auf Funktion und energiereiche Phosphatverbindungen des Meerschweinchen-herzens. Arzneim.-Forsch. 24, $928-932$ (1974)

15) Nickor.as, T.E.: Potentiation of the effects of noradrenaline and of sympathetic stimulation of the perfused rat caudal artery by angiotensin. J. Pharm. Pharmacol. 22, 37-41 (1970)

16) Regoli, D., Park, W.K. and Riolx, F.: Pharmacology of angiotensin. Pharmacol. Rev. 26, 69-123 (1974)

17) Kuchel, O., Cuche, J.L., Hamet, P., Barbeau, A., Boucher, R. And Genest, J.: Mechanisms of Hypertension, Edited by SAMBHI, M.P., p. 160-175, Excerpta Medica, Amsterdam (1973)

18) Rockson, S., Stonf, R., van der Wryden, M. and Kelley, W.N.: Lesch-Nyhan Syndrome - Evidence for abnormal adrenergic function. Science 186, 934-935 (1974)

19) Sakata, T. and Fuchimoto, H.: Stereotyped and aggressive behavior induced by sustained high dose of theophylline in rats. Japan. J. Pharmacol. 23, $781-785$ (1973)

20) Sircimillfr, J.E.: Purine metabolism. Arth. Rheum. 18, 681-686 (1975) 